\title{
AT1 Receptor Mediated Hypertensive Response to Ang II in the Nucleus Tractus Solitarii of Normotensive Rats Involves NO Dependent Local GABA Release
}

\section{OPEN ACCESS}

Edited by:

Carlos C. Crestani,

Universidade Estadual Paulista Júlio

de Mesquita Filho, Brazil

Reviewed by:

Ewa Krystyna

Szczepanska-Sadowska

Medical University of Warsaw, Poland

Mohammed H. Abdulla,

University College Cork, Ireland

*Correspondence: Laura Légat

laura.legat@vub.be, laura_legat@hotmail.com

Specialty section: This article was submitted to

Neuropharmacology,

a section of the journal

Frontiers in Pharmacology

Received: 29 November 2018 Accepted: 11 April 2019

Published: 03 May 2019

Citation:

Légat L, Smolders I and Dupont AG (2019) AT1 Receptor Mediated Hypertensive Response

to Ang II in the Nucleus Tractus Solitarii of Normotensive Rats Involves NO Dependent Local GABA Release.

Front. Pharmacol. 10:460. doi: 10.3389/fphar.2019.00460

\section{Laura Légat ${ }^{1,2,3 *}$, Ilse Smolders ${ }^{1}$ and Alain G. Dupont ${ }^{1,2,3}$}

${ }^{1}$ Department of Pharmaceutical Chemistry, Drug Analysis and Drug Information, Research Group Experimental Pharmacology, Center for Neurosciences, Vrije Universiteit Brussel, Brussels, Belgium, ${ }^{2}$ Cardiovascular Center, Universitair Ziekenhuis Brussel, Brussels, Belgium, ${ }^{3}$ Department of Clinical Pharmacology and Clinical Pharmacy, Universitair Ziekenhuis Brussel, Brussels, Belgium

Aim: It is well-established that angiotensin II exerts a dampening effect on the baroreflex within the nucleus tractus solitarii (NTS), the principal brainstem site for termination of baroreceptor afferents and which is densely populated with gamma-aminobutyric acid (GABA)ergic neurons and nerve terminals. The present study was designed to investigate whether local release of GABA is involved in the effects mediated by local angiotensin II within the NTS.

Methods: In vivo microdialysis was used for measurement of extracellular glutamate and GABA levels and for infusion of angiotensin II within the NTS of conscious normotensive Wistar rats. The mean arterial pressure (MAP) and heart rate response to local infusion of angiotensin II were subsequently monitored with a pressure transducer under anesthesia. The angiotensin II type 1 receptor (AT1R) antagonist, candesartan, was used to assess whether responses were AT1R dependent and the nitric oxide (NO) synthase inhibitor, $N(\omega)$-nitro-L-arginine methyl ester (L-NAME), was used to assess the involvement of $\mathrm{NO}$ in the evoked responses by infusion of angiotensin II. The MAP and heart rate responses were monitored with a pressure transducer.

Results: Local infusion into the NTS of angiotensin II induced a significant to ninefold significantly increase in extracellular GABA levels; as well as MAP was increased by $15 \mathrm{mmHg}$. These responses were both abolished by co-infusion of either, the angiotensin II type 1 receptor antagonist, candesartan, or the NO synthase inhibitor, L-NAME, demonstrating that the effect is not only AT1R dependent but also NO dependent. The pressor response to angiotensin II was reversed by co-infusion with the $\mathrm{GABA}_{\mathrm{A}}$ receptor antagonist, bicuculline. Local blockade of NO synthase decreased both, GABA and glutamate concentrations.

Conclusion: Our results suggest that the AT1R mediated hypertensive response to angiotensin II within the NTS in normotensive rats is GABA and NO dependent. Nitric oxide produced within the NTS tonically potentiates local GABA and glutamate release.

Keywords: angiotensin II, gamma-aminobutyric acid (GABA), mean arterial pressure, nucleus tractus solitarii, nitric oxide 


\section{INTRODUCTION}

The central nervous system network that regulates the level of sympathetic tone and, hence, blood pressure, is located in the brainstem and consists mainly of the rostral ventrolateral medulla (RVLM), the paraventricular nucleus (PVN) of the hypothalamus and the nucleus tractus solitarii (NTS) (Guyenet, 2006). It is well-established that the RVLM, the so-called brainstem 'pressor area', is a key site for the regulation of sympathetic tone and blood pressure (Dupont and Brouwers, 2010). The major source of excitatory sympathetic drive from the RVLM are spinally projecting glutamatergic neurons which receive tonic excitatory signals from other brain areas, including the PVN, and inhibitory signals from the caudal ventrolateral medulla (CVLM) and indirectly from the NTS (Guyenet, 2006). The NTS plays an important role in central cardiovascular regulation and is the principal site for the termination of baroreceptor afferent fibers mediating the inhibitory actions of baroreceptors in the arterial wall on sympathetic outflow (Paton and Kasparov, 1999; Guyenet, 2006). Stimulation of mechanosensitive baroreceptors by distension of the arterial wall following blood pressure elevation results in activation of glutamatergic neurons located in the NTS. The dampening effect on the barosensitive neurons of RVLM is mediated by the gamma-aminobutyric acid (GABA)-containing neurons of the CVLM, indicating a crucial role of GABA-mediated input from the CVLM for the baroreflex. The second-order NTS neurons indeed project to and activate GABAergic neurons within the CVLM, which have an inhibitory influence on RVLM neurons. Hence, baroreceptor mediated activation of NTS neurons indirectly inhibits the RVLM through activation of GABAergic neurons of the CVLM, ultimately resulting in a reduced sympathetic outflow with blood pressure and heart rate (HR) reduction (Guyenet, 2006).

The role of the brain renin-angiotensin system (RAS), and in particular of the angiotensin II type 1 receptor (AT1R), in the regulation of blood pressure and sympathetic tone is also well-established (Guyenet, 2006; Dupont and Brouwers, 2010). Brain angiotensin II (Ang II), acting through AT1Rs in different parts of the brain including the PVN and the RVLM, increases mean arterial pressure (MAP) and sympathetic nerve activity. There is clear evidence that brain Ang II increases blood pressure and sympathetic activity through stimulation of AT1Rs on spinally projecting glutamatergic neurons located in the RVLM (Hu et al., 2002; Dupont and Brouwers, 2010). Similarly, microinjection of Ang II in the PVN of the hypothalamus was repeatedly reported to increase blood pressure, HR and sympathetic activity, effects also mediated through AT1R stimulation (Tagawa and Dampney, 1999; Li et al., 2006; Dupont and Brouwers, 2010). There is also a high density of Ang II containing neurons and AT1Rs in the NTS, located presynaptically on carotid sinus afferents, on interneurons (Healy et al., 1989), and on catecholamine containing neurons (Yang et al., 1997). Microinjections of Ang II within the NTS were reported to result in decreases or increases in blood pressure depending on the volume, concentration or region of Ang II injection (Casto and Phillips, 1984a;
Rettig et al., 1986; Tan et al., 2007; Zhang et al., 2009). However, current evidence provided by several research groups clearly indicates that brain Ang II modulates the central integration of baroreceptor inputs within the NTS resulting in attenuation of baroreceptor sensitivity and dampening of baroreceptor reflexes and, hence, elevated blood pressure (Matsumura et al., 1998; Ferguson et al., 2001; Wong et al., 2002; Tan et al., 2005; Yao et al., 2008).

It has been postulated that the Ang II mediated reduction in baroreceptor feedback could be due to a biasing of the transmission between baroreceptor afferents and second-order neurons in the NTS, mediated by increased inhibitory GABAergic neurotransmission (Paton et al., 2001a; Guyenet, 2006). The brain GABAergic system is indeed also known to play a key role in cardiovascular regulation (Yao et al., 2008). The NTS is densely populated with GABAergic neurons, GABAergic nerve terminals (Bailey et al., 2008) as well as with $\mathrm{GABA}_{\mathrm{A}^{-}}$and $\mathrm{GABA}_{\mathrm{B}^{-}}$receptors (Zhang et al., 2009), suggesting an important modulatory role of GABA within the NTS (Zhang et al., 2009). GABAergic neurons have been identified as the predominant intrinsic network co-ordinating cardiovascular functions within the NTS (Potts et al., 2003; Bailey et al., 2008; Dufour et al., 2010). Microinjections of $G A B A_{B}$ receptor agonists within the NTS produce a pressor response, whereas $G_{A B A}$ receptor antagonists produce a depressor response (Vitela and Mifflin, 2001; Mei et al., 2003; Zhang et al., 2009). Zhang et al. (2009) reported that chronic intracerebroventricular (icv) infusion of Ang II increased the expression of $\mathrm{GABA}_{\mathrm{B}}$ receptors within the NTS and enhanced the pressor response to a $\mathrm{GABA}_{\mathrm{B}}$ receptor agonist injected into the NTS (Zhang et al., 2009). Paton et al. (2001a) reported that the attenuating effect of Ang II applied in the NTS on the baroreceptor reflex was prevented by $\mathrm{GABA}_{\mathrm{A}}$ receptor antagonism with bicuculline (Paton et al., 2001a), suggesting that the dampening effect of Ang II within the NTS could be GABA dependent and that $\mathrm{GABA}_{\mathrm{A}}$ receptor stimulation is involved. Hence, there is evidence indicating that actions of GABA and Ang II within the NTS on blood pressure are similar (Yao et al., 2008), suggesting that these neuromediators may interact within the NTS to influence the sympathetic tone. Nevertheless, in none of these above mentioned studies GABA concentrations were measured.

Our main objective was therefore to further test this hypothesis using microdialysis to investigate the responses evoked by Ang II infusion within the NTS in normotensive Wistar rats. We assessed blood pressure and HR changes and possible effects on local glutamate and GABA concentrations in response to unilateral administration of Ang II within the NTS. Further, as Ang II and GABA are both known to interact with nitric oxide (NO) in other brain area's (Dupont and Brouwers, 2010), and as NO was suggested to be involved in the Ang II mediated modulation of the baroreceptor reflex pathway (Paton et al., 2001a), we also aimed to investigate the possible role of the NO-pathway in the responses evoked by AT1R activation within the NTS. 


\section{MATERIALS AND METHODS}

\section{Animals}

All experiments were performed on normotensive male albino Wistar rats (Charles River Laboratories, L'Arbresle, France) weighing 250-300 g at time of surgery. Animals acclimatized at least 1 week to the animal facility before surgery at constant temperature $\left(22 \pm 3^{\circ} \mathrm{C}\right)$, a relative humidity of $55 \%( \pm 10 \%)$, a $12 \mathrm{~h}$ light-dark cycle and with free access to water and food (Safe $\mathrm{A}_{04}$ maintenance diet). The sodium content of the food was $2.500 \mathrm{mg} / \mathrm{kg}$ implying that the daily sodium intake was approximately $54 \mathrm{mg}$ per day. All procedures used and described for animal experiments were carried out in accordance with the National and European guidelines for animal experimental research $(2010 / 63 / \mathrm{EU})$ and were approved by the Ethical Committee for Animal Experiments of the Vrije Universiteit Brussel, Belgium (Project No. 18-213-1). All efforts were made to avoid animal suffering. To minimize the number of animals used, each animal was used for microdialysis sampling as well as for MAP measurement and control/baseline period before - and a wash out period after compound administration in the same animal. The number of rats used for each experiment was based on power calculations, which were approved by the Ethical Committee. In accordance with the ARRIVE Guidelines (Kilkenny et al., 2010) and the general policy at our institution, the number of animals used for each experiment was kept to the minimum required to allow for clear and valid conclusions.

\section{Drugs}

Ang II, bicuculline and $N(\omega)$-nitro-L-arginine methyl ester (L-NAME) were purchased from Sigma Aldrich, Co. (St. Louis, MO, United States). Ang II was used as an AT1R agonist, bicuculline as a $\mathrm{GABA}_{\mathrm{A}}$ receptor antagonist and L-NAME as an inhibitor of NO-synthase (NOS). Candesartan was used as a competitive-insurmountable AT1R antagonist (Tocris Bioscience, Bristol, United Kingdom). Infusion doses of Ang II, bicuculline, L-NAME and candesartan were selected based on previous studies (Ogawa et al., 1995; Smolders et al., 1995a; Mertens et al., 2010; Brouwers et al., 2015).

The treatment compounds [Ang II (1 and $\left.3 \mu \mathrm{g} \mu \mathrm{L}^{-1} \mathrm{~h}^{-1}\right)$, candesartan (0.5 and $\left.1.5 \mathrm{ng} \mu \mathrm{L}^{-1} \mathrm{~h}^{-1}\right)$, Ang II (1 and $\left.3 \mu \mathrm{g} \mu \mathrm{L}^{-1} \mathrm{~h}^{-1}\right)+$ candesartan $\left(0.5 \mathrm{ng} \mu \mathrm{L}^{-1} \mathrm{~h}^{-1}\right)$, Ang II (3 $\left.\mu \mathrm{g} \mu \mathrm{L}^{-1} \mathrm{~h}^{-1}\right)+$ candesartan $\left(1.5 \mathrm{ng} \mu \mathrm{L}^{-1} \mathrm{~h}^{-1}\right)$, Ang II (3 $\left.\mu \mathrm{g} \mu \mathrm{L}^{-1} \mathrm{~h}^{-1}\right)+$ bicuculline $\left(4 \mu \mathrm{g} \mu \mathrm{L}^{-1} \mathrm{~h}^{-1}\right)$, bicuculline (4 $\mu \mathrm{g} \mu \mathrm{L}^{-1} \mathrm{~h}^{-1}$ ), Ang II $\left(3 \mu \mathrm{g} \mu \mathrm{L}^{-1} \mathrm{~h}^{-1}\right)+\mathrm{L}-\mathrm{NAME}$ $\left(0.4 \mu \mathrm{g} \mu \mathrm{L}^{-1} \mathrm{~h}^{-1}\right)$, L-NAME $\left.\left(0.4 \mu \mathrm{g} \mu \mathrm{L}^{-1} \mathrm{~h}^{-1}\right)\right]$ were dissolved in modified Ringer's solution (147 mM NaCl, $2.3 \mathrm{mM} \mathrm{CaCl}$, $4 \mathrm{mM} \mathrm{KCl}$ ) and perfused at a flow rate of $2 \mu \mathrm{L} \mathrm{min}^{-1}$ through the microdialysis probe.

\section{Experimental Design (Figure 1)}

Day 1: Following acclimatization, rats were subjected to stereotactic implantation of a microdialysis guide cannula as described in section "Surgery." A guide cannula was replaced by a microdialysis probe to locally infuse drugs and collect dialysate for the measurement of neurotransmitters. After surgery, the animals recovered overnight.

Day 2: Microdialyis should restricted to a narrow time window (16-48 h) in order to reestablish blood brain barrier integrity and preceed gliotic reactions. Based on several studies (Benveniste and Diemer, 1987; Grabb et al., 1998; Schiffer et al., 2006; Sumbria et al., 2011) microdialysis sampling was initiated $24 \mathrm{~h}$ after probe implantation. All samples were analyzed by liquid chomatography (LC) for measurement of glutamate and GABA.

Day 3: The same rats as used for microdialysis experiments were anesthetized prior to cannulation of the right carotid artery for continuous monitor the MAP and HR as described in section "Mean Arterial Pressure and Heart Rate Measurement."

\section{Surgery}

On the first day of the experiment, all animals were anesthetized prior to surgery with ketamine/diazepam mixture $(90 / 4.5 \mathrm{mg} / \mathrm{kg}$ ) intraperitoneally and received $4 \mathrm{mg} / \mathrm{kg}$ ketoprofen subcutaneously to prevent post-operative pain and inflammation. A stainless steel microdialysis guide cannula (CMA12, Solna, Sweden) was stereotactically implanted $2 \mathrm{~mm}$ above the left NTS (from bregma: anterior-posterior: $1.30 \mathrm{~mm}$, medial-lateral: $-12.8 \mathrm{~mm}$, and $-5.6 \mathrm{~mm}$ below dura mater), as described previously (Légat et al., 2017).

\section{In vivo Microdialysis Experiment}

After recovery from the stereotactical guide implantation, rats were single housed in experimental cages with free access to food and water and the microdialysis probe (CMA12/1 mm membrane length, Solna, Sweden) was inserted into the guide-cannula. The microdialysis probe was connected by tubings (Microbiotech/se $\mathrm{AB}$, Stockholm, Sweden) to a micro-injection pump (BAS MD-1001). The microdialysis probe was continuously perfused overnight at a flow rate of $1 \mu \mathrm{L} \mathrm{min}{ }^{-1}$ with modified Ringer's solution (147 mM NaCl, $2.3 \mathrm{mM} \mathrm{CaCl}_{2}, 4 \mathrm{mM} \mathrm{KCl}$ ). On the second day, dialysis samples were collected from freely moving rats allowing us to measure neurotransmitters at many time points in each animal. Samples were taken every $20 \mathrm{~min}$ and each experiment lasted for $6 \mathrm{~h}$. Each experiment started with the collection of intracerebral baseline samples (1-6) for $2 \mathrm{~h}$, during which the perfusion fluid was composed of modified Ringer's solution. Consecutively, treatment compounds dissolved in modified Ringer's solution were perfused through the microdialysis probe from the $7^{\text {th }}$ collection period onward until the $12^{\text {th }}$ collection. Finally, samples $(13-18)$ were taken under infusion of Ringer's solution alone.

\section{Liquid Chromatography Method for Glutamate and GABA Analysis}

Glutamate and GABA concentrations were measured in the dialysates using respectively, reversed-phase narrowbore LC with gradient elution and fluorescence detection and reversed-phase microbore LC with isocratic elution and electrochemical detection, as described in detail in previous publications (Smolders et al., 1995b; Van Hemelrijck et al., 2005; Légat et al., 2017). 


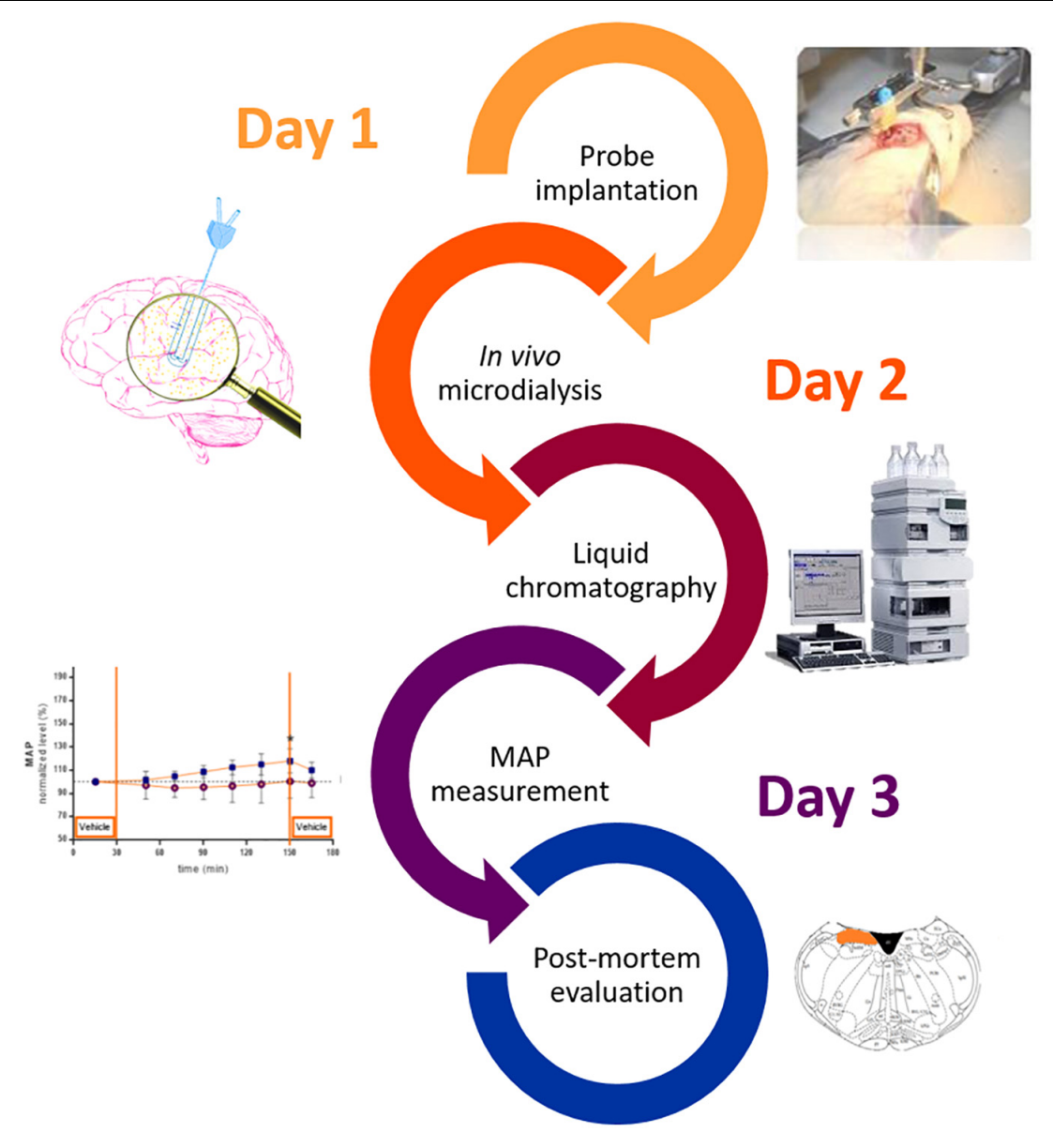

FIGURE 1 | Overview experimental design.

\section{Mean Arterial Pressure and Heart Rate Measurement}

On the third day of the experiment, animals were anesthetized by $4 \%$ sevuflurane gas in order to continuously record MAP and $\mathrm{HR}$ via cannulation of the right carotid artery using a pressure transducer connected to a monitor (Phillips IntelliVue MP50) as described previously (Légat et al., 2017). The right jugular vein was catheterized for fluid maintenance $(0.9 \% \mathrm{NaCl})$. The experimental protocol started after a $30 \mathrm{~min}$ equilibration period following cannulation. Anesthesia was maintained by $2 \%$ sevoflurane administration. First the baseline values were recorded for $30 \mathrm{~min}$ before the $2 \mathrm{~h}$ administration of the compounds. Finally, values were recorded under infusion of Ringer's solution alone during $30 \mathrm{~min}$.

\section{Post-mortem Evaluation}

At the end of every experiment, rats were sacrificed by an overdose of pentobarbital (Dolethal, Vétoquinol, Lure, France). Removed rat brains were kept on $4 \%$ paraformaldehyde solution. Probe localization was histologically verified after brain slicing by a neutral red staining compared against an anatomic atlas
(Paxinos and Watson, 1998) in order to exclude animals with inaccurately implanted probes (Supplementary Figure S1).

\section{Data Analyses and Statistics}

Statistical analyses were performed using GraphPad Prism 6.01 (GraphPad Software, Inc., San Diego, CA, United States) with the $\alpha$ level chosen at 0.05 . Data are expressed as mean \pm standard error of the mean (SEM). The mean values of the basal microdialysis samples as well as of the baseline MAP and HR obtained before compound administration were considered as the $100 \%$ baseline value for each animal. Results for the neurotransmitters, glutamate and GABA, were expressed as percentages of the baseline levels \pm SEM. Subsequently, for the microdialysis results, an area under the curve (AUC) analysis was performed to determine if there was a difference in GABA concentrations. AUC values, expressed in arbitrary units, were compared by a Friedman test with Dunnett's multiple comparison post hoc test. All MAP and HR measurements were also shown as percentage of the baseline levels \pm SEM. To determine intragroup differences, data were analyzed applying a Friedman test followed by the Dunnett's multiple comparison test. 


\section{RESULTS}

\section{Angiotensin II Within the NTS Increases Extracellular GABA Levels}

In a first series of experiments we investigated the effect of local Ang II infusion in two different doses (1 or $3 \mu \mathrm{g} \mu \mathrm{L}^{-1} \mathrm{~h}^{-1}$ ) within the NTS on extracellular glutamate (Figure 2A) and GABA (Figure 2B) levels. Extracellular neurotransmitter concentrations were monitored under basal condition $(0-120 \mathrm{~min})$ as well as during and after administration of Ang II (120-240 min). No changes from baseline concentrations were seen for glutamate levels during Ang II infusion within the NTS $\left[n=7\left(1 \mu \mathrm{g} \mu \mathrm{L}^{-1} \mathrm{~h}^{-1}\right) ; n=6\left(3 \mu \mathrm{g} \mu \mathrm{L}^{-1} \mathrm{~h}^{-1}\right)\right.$; Figure 2A]. GABA levels tended to increase during infusion of $1 \mu \mathrm{g} \mu \mathrm{L}^{-1} \mathrm{~h}^{-1}$ Ang II within the NTS $(n=8$; Figure 2B). Infusion of $3 \mu \mathrm{g} \mu \mathrm{L}^{-1} \mathrm{~h}^{-1}$ Ang II within the NTS induced a significant increase in GABA levels $(n=6 ; p<0.05-0.01$ compared to vehicle; Figure 2B).

\section{Angiotensin II-Evoked Increase in GABA Is Abolished by AT1R Antagonism Within the NTS}

Subsequently, the responses to two different doses (0.5 or $1.5 \mathrm{ng} \mu \mathrm{L}^{-1} \mathrm{~h}^{-1}$ ) of the AT1R antagonist candesartan alone and during co-infusion with the two doses of Ang II were tested (Figure 3). Extracellular glutamate and GABA levels were not significantly different from the mean baseline levels during infusion with either of the two different doses ( 1 or $3 \mu \mathrm{g} \mu \mathrm{L}^{-1} \mathrm{~h}^{-1}$ ) of candesartan alone (data not shown). The previously observed trend to an increase in GABA during infusion of $1 \mu \mathrm{g} \mu \mathrm{L}^{-1} \mathrm{~h}^{-1}$ Ang II was not seen during co-infusion with $0.5 \mathrm{ng} \mu \mathrm{L}^{-1} \mathrm{~h}^{-1}$ candesartan $(n=5$; Figure 3B). The GABA response to $3 \mu \mathrm{g} \mu \mathrm{L}^{-1} \mathrm{~h}^{-1}$ Ang II was attenuated and not statistically significant during co-infusion with $0.5 \mathrm{ng} \mu \mathrm{L}^{-1} \mathrm{~h}^{-1}$ candesartan (data not shown). Glutamate concentrations were not altered by co-infusion of
$0.5 \mathrm{ng} \mu \mathrm{L}^{-1} \mathrm{~h}^{-1}$ candesartan with $1 \mu \mathrm{g} \mu \mathrm{L}^{-1} \mathrm{~h}^{-1}$ Ang II ( $n=5$; Figure 3A). Co-infusion of $1.5 \mathrm{ng} \mu \mathrm{L}^{-1} \mathrm{~h}^{-1}$ of AT1R antagonist, candesartan, with $3 \mu \mathrm{g} \mu \mathrm{L}^{-1} \mathrm{~h}^{-1}$ Ang II did not alter the glutamate concentrations ( $n=5$; Figure $3 \mathbf{A})$, but abolished the Ang II evoked increase in GABA concentrations $(n=5$; Figure 3B) within the NTS.

The AUC values of GABA dialysate levels tended to increase during $1 \mu \mathrm{g} \mu \mathrm{L}^{-1} \mathrm{~h}^{-1}$ Ang II infusion $(n=8$; Figure $4 \mathrm{~A})$; the higher dose of Ang II $\left(3 \mu \mathrm{g} \mu \mathrm{L}^{-1} \mathrm{~h}^{-1}\right)$ significantly increased the GABA levels ( $n=6 ; p<0.01$ compared to vehicle; Figure 4B). The AUC values of GABA during co-infusion of Ang II with $0.5 \mathrm{ng} \mu \mathrm{L}^{-1} \mathrm{~h}^{-1}$ candesartan $(n=5$; Figure $4 \mathrm{C})$ or $1.5 \mathrm{ng} \mu \mathrm{L}^{-1} \mathrm{~h}^{-1}(n=5$; Figure $4 \mathrm{D})$ were not different compared to the AUC values during vehicle infusion, indicating that the GABA increase induced by the higher dose of Ang II was abolished by local AT1R antagonism with high dose candesartan.

\section{AT1R-Evoked Increase in GABA Is Abolished by NO Synthase Inhibition Within the NTS}

To evaluate the possible involvement of $\mathrm{NO}$ in the AT1R mediated GABA release within the NTS, the response to the NOS inhibitor, L-NAME $\left(0.4 \mu \mathrm{g} \mu \mathrm{L}^{-1} \mathrm{~h}^{-1}\right)$, was tested alone and during co-infusion with $3 \mu \mathrm{g} \mu \mathrm{L}^{-1} \mathrm{~h}^{-1}$ Ang II (Figure 5). L-NAME $\left(0.4 \mu \mathrm{g} \mu \mathrm{L}^{-1} \mathrm{~h}^{-1}\right)$ alone significantly ( $p<0.05-0.01$ compared to vehicle) reduced baseline glutamate levels $(n=5$; Figure 5A). Glutamate levels during co-infusion of $0.4 \mu \mathrm{g} \mu \mathrm{L}^{-1} \mathrm{~h}^{-1} \mathrm{~L}$-NAME with $3 \mu \mathrm{g} \mu \mathrm{L}^{-1} \mathrm{~h}^{-1}$ Ang II were also significantly ( $p<0.05-0.01$ compared to vehicle) reduced but not different from levels during L-NAME $\left(0.4 \mu \mathrm{g} \mu \mathrm{L}^{-1} \mathrm{~h}^{-1}\right)$ alone $(n=5$; Figure $5 \mathrm{~A})$. Infusion of $0.4 \mu \mathrm{g} \mu \mathrm{L}^{-1} \mathrm{~h}^{-1} \mathrm{~L}$-NAME alone tended to decrease GABA levels $(n=5$; Figure $5 \mathrm{~B})$,

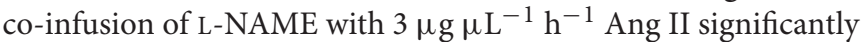
( $p<0.05-0.01$ compared to vehicle) decreased the GABA levels and reversed the Ang II evoked increase in GABA within the NTS $(n=5$; Figure 5B).
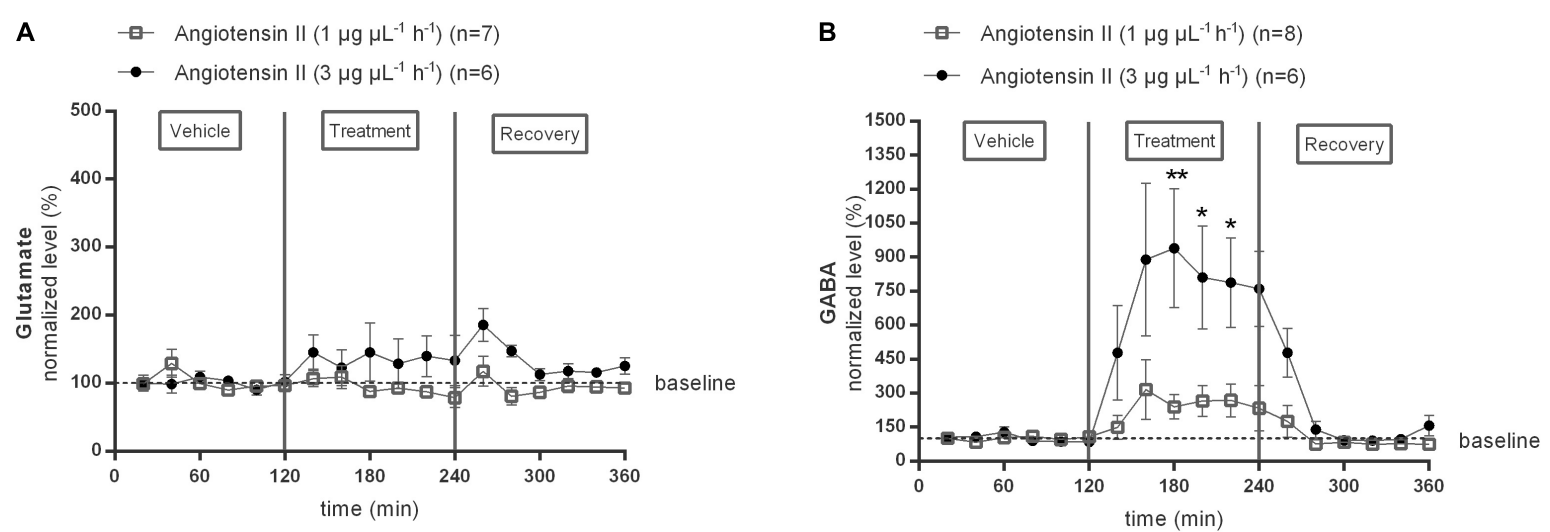

FIGURE 2 | Effect of Ang II infusion (120-240 min) within the NTS on the extracellular glutamate (A) and GABA (B) concentrations in normotensive freely moving

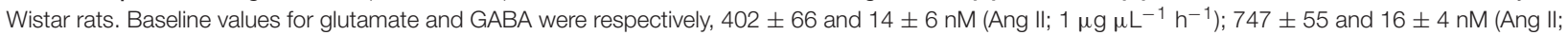
$3 \mu \mathrm{g} \mu \mathrm{L}^{-1} \mathrm{~h}^{-1}$ ). Data are presented as mean percentage of baseline levels \pm SEM. Statistical analysis is performed using the Friedman test and the Dunnett's mutiple comparison test. Local Ang II $\left(3 \mu \mathrm{g} \mu \mathrm{L}^{-1} \mathrm{~h}^{-1}\right)$ infusion significantly increased GABA levels, with ${ }^{*} p<0.05,{ }^{* *} p<0.01$ compared to vehicle control. 


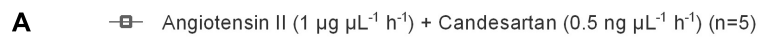

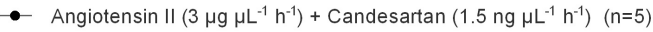

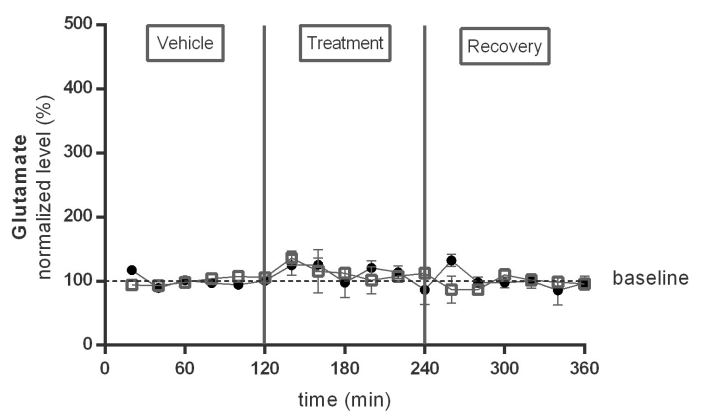

B

$\because$ Angiotensin II $\left(1 \mu \mathrm{g} \mu \mathrm{L}^{-1} \mathrm{~h}^{-1}\right)+$ Candesartan $\left(0.5 \mathrm{ng} \mathrm{\mu L}^{-1} \mathrm{~h}^{-1}\right) \quad(\mathrm{n}=5)$

- Angiotensin II $\left(3 \mu g \mathrm{~L}^{-1} \mathrm{~h}^{-1}\right)+$ Candesartan $\left(1.5 \mathrm{ng} \mathrm{\mu L}^{-1} \mathrm{~h}^{-1}\right) \quad(\mathrm{n}=5)$

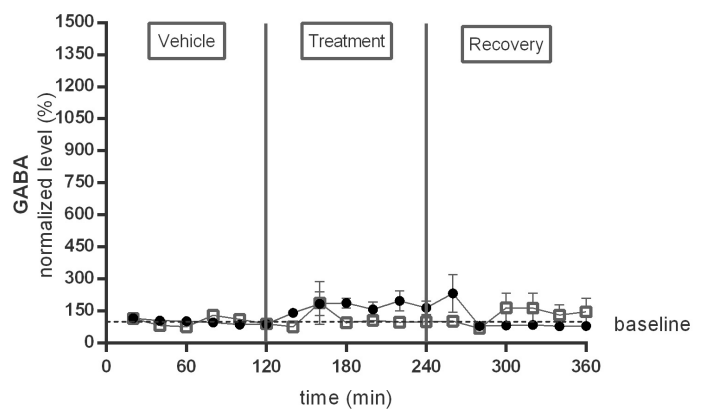

FIGURE 3 | Effect of co-infusion of candesartan with Ang II (120-240 min) within the NTS on the extracellular glutamate (A) and GABA (B) concentrations in normotensive freely moving Wistar rats. Baseline values for glutamate and GABA were respectively, $724 \pm 124$ and $12 \pm 8 \mathrm{nM}^{(\mathrm{Ang} \|} \mathrm{I} ; \mu \mathrm{g} \mu \mathrm{L}^{-1} \mathrm{~h}^{-1}+$ candesartan $0.5 \mathrm{ng} \mu \mathrm{L}^{-1} \mathrm{~h}^{-1}$ ); $473 \pm 217$ and $17 \pm 11 \mathrm{nM}$ (Ang II; $3 \mu \mathrm{g} \mu \mathrm{L}^{-1} \mathrm{~h}^{-1}+$ candesartan $1.5 \mathrm{ng} \mu \mathrm{L}^{-1} \mathrm{~h}^{-1}$ ). Data are presented as the mean percentage of baseline levels \pm SEM. Statistical analysis is performed using the Friedman test and the Dunnett's mutiple comparison test.
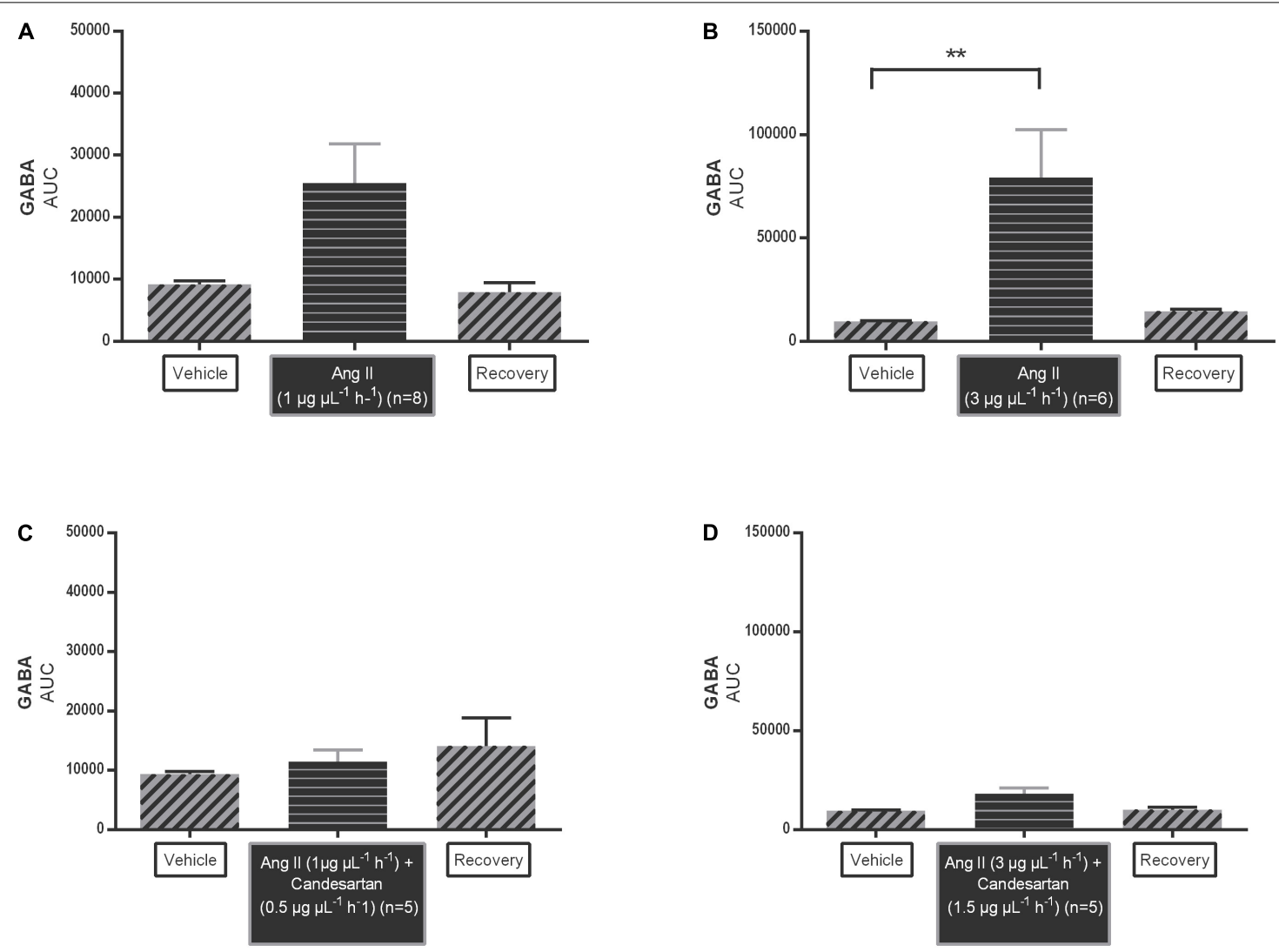

FIGURE 4 | Area under the curve (AUC) values of Ang II infusion $\left[1 \mu \mathrm{g} \mu \mathrm{L}^{-1} \mathrm{~h}^{-1}\right.$ (A) and $3 \mu \mathrm{g} \mu \mathrm{L}^{-1} \mathrm{~h}^{-1}$ (B)] and in co-infusion with candesartan [0.5 $\mathrm{ng} \mu \mathrm{L}^{-1} \mathrm{~h}^{-1}$ (C) and $1.5 \mathrm{ng} \mu \mathrm{L}^{-1} \mathrm{~h}^{-1}$ (D)] applied by microdialysis within the NTS in normotensive freely moving Wistar rats on extracellular GABA. Data are represented as the mean AUC \pm SEM. Statistical analysis is performed using the Friedman test with Dunnett's multiple comparison test. Local Ang II $\left(3 \mu g \mu L^{-1} \mathrm{~h}^{-1}\right)$ infusion significantly increased GABA levels, with ** $p<0.01$ compared to vehicle control.

\section{MAP and HR Response to Ang II Infusion Within the NTS}

The effect of local 1 or $3 \mu \mathrm{g} \mu \mathrm{L}^{-1} \mathrm{~h}^{-1}$ Ang II infusion through microdialysis within the NTS on MAP (Figure 6A) and HR
(Figure 6B) was assessed under anesthesia in the same rats, equipped with a microdialysis probe within the NTS, as used for the previous experiment. MAP tended to increase during infusion of $1 \mu \mathrm{g} \mu \mathrm{L}^{-1} \mathrm{~h}^{-1}$ Ang II within the NTS $(n=5$; Figure 6A) 

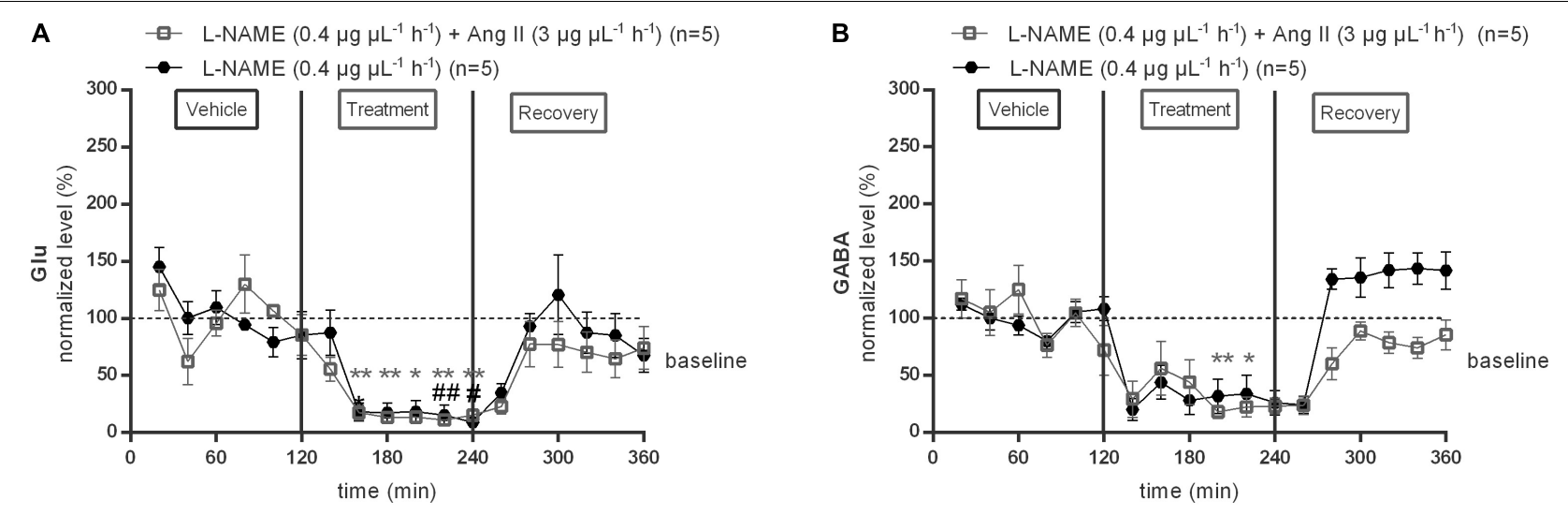

FIGURE 5 | Effect of co-infusion of L-NAME with Ang II (120-240 min) within the NTS on the extracellular glutamate (A) and GABA (B) concentrations in normotensive freely moving Wistar rats. Baseline values for glutamate and GABA were respectively, $287 \pm 113$ and $15 \pm 6 \mathrm{nM}\left(\mathrm{L}_{-} \mathrm{NAME} ; 0.4 \mu \mathrm{g} \mu \mathrm{L}^{-1} \mathrm{~h}^{-1}\right.$ ); $1431 \pm 149$ and $10 \pm 4 \mathrm{nM}$ (Ang II; $3 \mu \mathrm{g} \mu \mathrm{L}^{-1} \mathrm{~h}^{-1}+\mathrm{L}$-NAME $0.4 \mu \mathrm{g} \mu \mathrm{L}^{-1} \mathrm{~h}^{-1}$ ). Data are presented as the mean percentage of baseline levels vehicle \pm SEM. Statistical analysis is performed using the Friedman test and the Dunnett's mutiple comparison test. Local L-NAME $\left(0.4 \mu \mathrm{g} \mu \mathrm{L}^{-1} \mathrm{~h}^{-1}\right)$ infusion significantly decreased glutamate and GABA levels, with ${ }^{\#} p<0.05$; ${ }^{\# \#} p<0.01$ compared to vehicle control. Local L-NAME $\left(0.4 \mu \mathrm{g} \mu \mathrm{L}^{-1} \mathrm{~h}^{-1}\right)$ in co-infusion with Ang $\|$ (3 $\left.\mu \mathrm{g} \mu \mathrm{L}^{-1} \mathrm{~h}^{-1}\right)$ significantly decreased glutamate levels, with $* p<0.05 ;{ }^{* *} p<0.01$ compared to vehicle control.
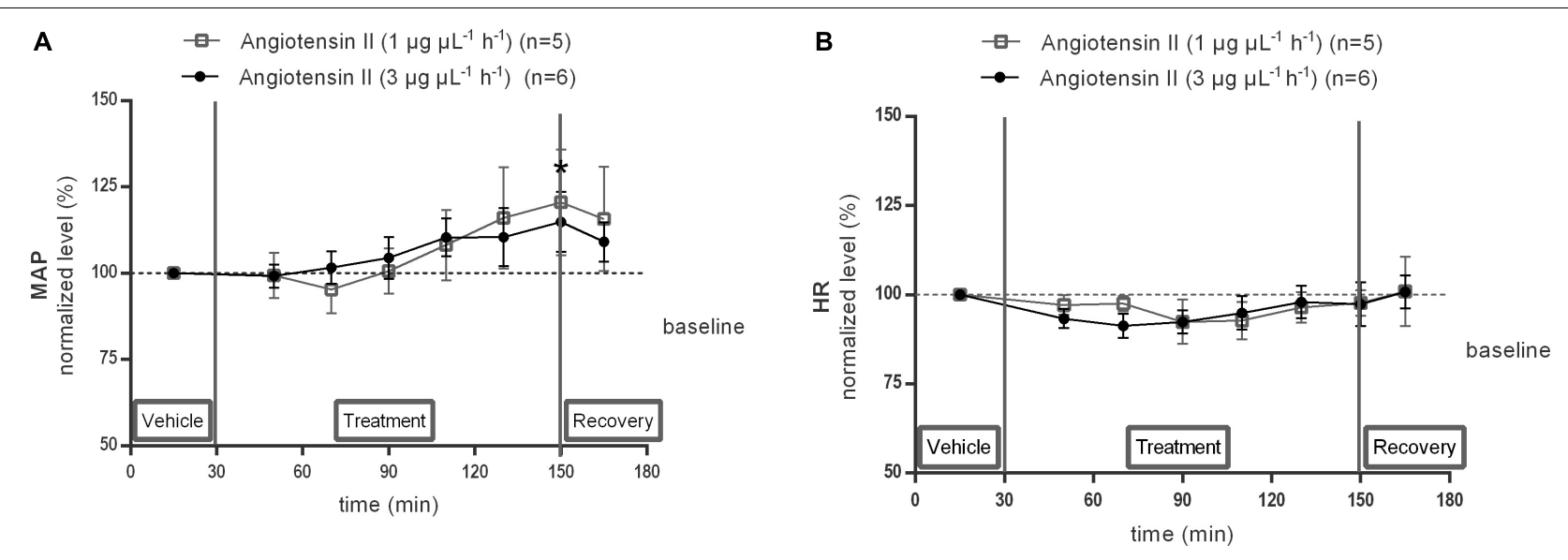

FIGURE 6 | Effect of Ang II infusion (120-240 min) within the NTS on MAP (A) and HR (B) in anesthetized normotensive Wistar rats. Baseline MAP and HR were respectively, $84 \pm 24 \mathrm{mmHg}$ and $434 \pm 19 \mathrm{bpm}$ (Ang $\| ; 1 \mu \mathrm{g} \mu \mathrm{L}^{-1} \mathrm{~h}^{-1}$ ); $82 \pm 9 \mathrm{mmHg}$ and $410 \pm 83 \mathrm{bpm}\left(\right.$ Ang $\| ; 3 \mu \mathrm{g} \mu \mathrm{L}^{-1} \mathrm{~h}^{-1}$ ). Data are presented as the mean percentage of baseline levels \pm SEM. Statistical analysis is performed using the Friedman test and the Dunnett's mutiple comparison test. Local Ang $I$ $\left(3 \mu \mathrm{g} \mu \mathrm{L}^{-1} \mathrm{~h}^{-1}\right)$ infusion significantly increased MAP, with * $p<0.05$ compared to vehicle control.

and increased significantly during infusion of $3 \mu \mathrm{g} \mu \mathrm{L}^{-1} \mathrm{~h}^{-1}$ Ang II at time point $150 \mathrm{~min}(+15 \mathrm{mmHg}$ compared to vehicle after 120 min Ang II infusion; $n=6$; $p<0.05$; Figure 6A). HR did not change during infusion of $1 \mu \mathrm{g} \mu \mathrm{L}^{-1} \mathrm{~h}^{-1}(n=5)$ or $3 \mu \mathrm{g} \mu \mathrm{L}^{-1} \mathrm{~h}^{-1}(n=6)$ of Ang II compared to vehicle (Figure 6B).

\section{MAP and HR Response to Co-infusion of Ang II With Candesartan Within the NTS}

The responses of MAP (Figure 7A) and HR (Figure 7B) to 0.5 or $1.5 \mathrm{ng} \mu \mathrm{L}^{-1} \mathrm{~h}^{-1}$ of the AT1R antagonist candesartan alone and during co-infusion within the NTS with 1 or $3 \mu g \mu L^{-1} h^{-1}$ of Ang II were tested. Local infusion of candesartan alone within the NTS did not modify the baseline MAP nor HR (data not shown). There were no significant differences in MAP nor HR between vehicle and co-infusion of $1.5 \mathrm{ng} \mu \mathrm{L}^{-1} \mathrm{~h}^{-1}$ candesartan with $3 \mu \mathrm{g} \mu \mathrm{L}^{-1} \mathrm{~h}^{-1}$ Ang II $(n=5$; Figures 7A,B), indicating that the hypertensive response to $3 \mu \mathrm{g} \mu \mathrm{L}^{-1} \mathrm{~h}^{-1}$ of Ang II alone was abolished by AT1R antagonism (Figure 7A).

\section{MAP and HR Response to Co-infusion of Ang II With the GABA Receptor Antagonist Bicuculline Within the NTS}

Local infusion of $\mathrm{GABA}_{\mathrm{A}}$ receptor antagonist, bicuculline (4 $\mu \mathrm{g} \mu \mathrm{L}^{-1} \mathrm{~h}^{-1}$ ), alone within the NTS did not modify the baseline MAP nor HR (data not shown). Co-infusion

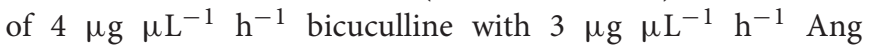
II significantly decreased the MAP at time point $110 \mathrm{~min}$ ( $-7 \mathrm{mmHg}$ compared to vehicle after $80 \mathrm{~min}$ co-infusion of Ang 
$\because$ Angiotensin II $\left(1.5 \mu g \mu \mathrm{L}^{-1} \mathrm{~h}^{-1}\right)+$ Candesartan $\left(0.5 \mathrm{ng} \mathrm{\mu L}^{-1} \mathrm{~h}^{-1}\right)(\mathrm{n}=5)$

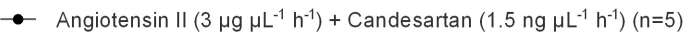

A

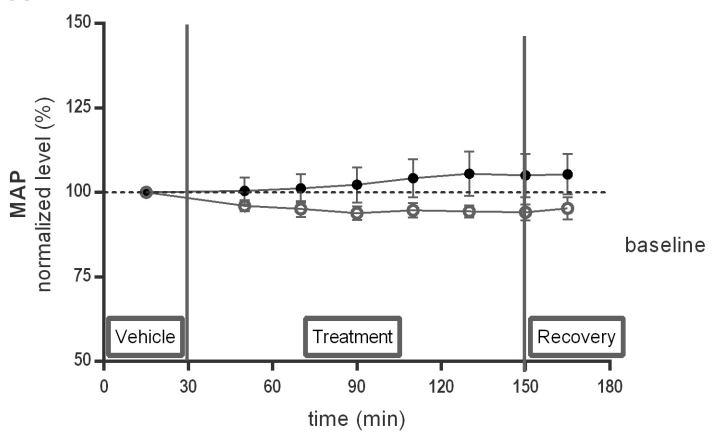

- Angiotensin II $\left(1 \mu \mathrm{g} \mu \mathrm{L}^{-1} \mathrm{~h}^{-1}\right)+$ Candesartan $\left(0.5 \mathrm{ng} \mu \mathrm{L}^{-1} \mathrm{~h}^{-1}\right)(\mathrm{n}=5)$

- Angiotensin II $\left(3 \mu g \mathrm{LL}^{-1} \mathrm{~h}^{-1}\right)+$ Candesartan $\left(1.5 \mathrm{ng} \mathrm{\mu L}^{-1} \mathrm{~h}^{-1}\right)(\mathrm{n}=5)$

B

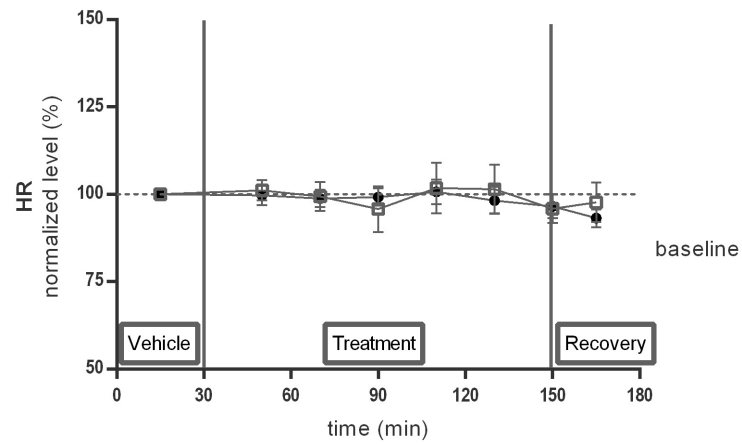

FIGURE 7 | Effect of co-infusion of candesartan with Ang II (120-240 min) within the NTS on MAP (A) and HR (B) in anesthetized normotensive Wistar rats. Baseline MAP and $\mathrm{HR}$ were respectively, $97 \pm 15 \mathrm{mmHg}$ and $430 \pm 46 \mathrm{bpm}$ (Ang $\| ; 1 \mu \mathrm{g} \mu \mathrm{L}^{-1} \mathrm{~h}^{-1}+{\text { candesartan } 0.5 \mathrm{ng} \mu \mathrm{L}^{-1} \mathrm{~h}}^{-1}$ ); $85 \pm 12 \mathrm{mmHg}$ and $412 \pm 34 \mathrm{bpm}$ (Ang II; $3 \mu \mathrm{g} \mu \mathrm{L}^{-1} \mathrm{~h}^{-1}$ ) + candesartan $1.5 \mathrm{ng} \mu \mathrm{L}^{-1} \mathrm{~h}^{-1}$ ). Data are presented as the mean percentage of baseline levels \pm SEM. Statistical analysis is performed using the Friedman test and the Dunnett's mutiple comparison test.
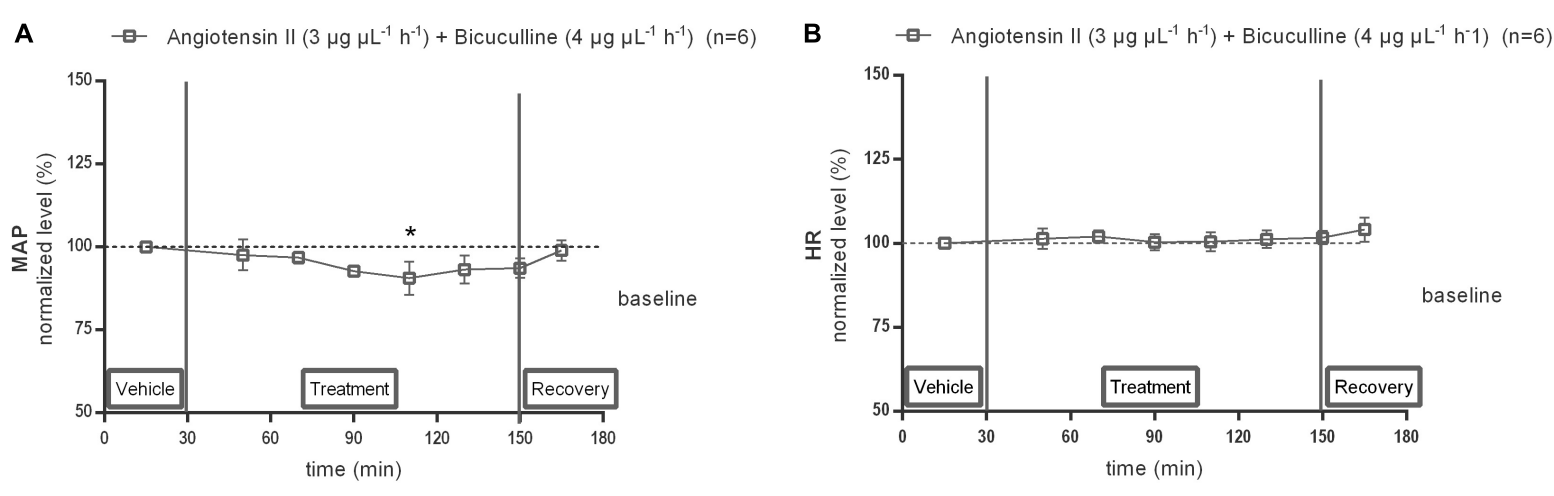

FIGURE 8 | Effect of co-infusion of bicuculline with Ang II (120-240 min) within the NTS on MAP (A) and HR (B). Baseline MAP and HR were respectively, $87 \pm 11 \mathrm{mmHg}$ and $411 \pm 50 \mathrm{bpm}$ (Ang $\| ; 3 \mu \mathrm{g} \mu \mathrm{L}^{-1} \mathrm{~h}^{-1}+$ bicuculline $4 \mu \mathrm{g} \mu \mathrm{L}^{-1} \mathrm{~h}^{-1}$ ). Data are presented as the mean percentage of baseline levels vehicle \pm SEM. Statistical analysis is performed using the Friedman test and the Dunnett's mutiple comparison test. Local co-infusion of bicuculline $\left(4 \mu \mathrm{g} \mu \mathrm{L}^{-1} \mathrm{~h}^{-1}\right)$ with Ang II $\left(3 \mu \mathrm{g} \mu \mathrm{L}^{-1} \mathrm{~h}^{-1}\right)$ significantly decreased MAP, with * $p<0.05$ compared to vehicle control.

II with bicuculline; $n=6 ; p<0.05$; Figure 8A) and reversed the Ang II evoked increase in MAP seen in Figure 6A, but did not affect the HR ( $n=6$; Figure 8B).

\section{MAP and HR Response to Co-infusion of Ang II With the NO-Synthase Inhibitor L-NAME Within the NTS}

Local infusion of L-NAME $\left(0.4 \mu \mathrm{g} \mu \mathrm{L}^{-1} \mathrm{~h}^{-1}\right)$ alone within the NTS did not modify baseline MAP $(n=5)$ nor HR $(n=4)$. Co-infusion of L-NAME abolished the MAP increase induced by $3 \mu \mathrm{g} \mu \mathrm{L}^{-1} \mathrm{~h}^{-1}$ Ang II $(n=5$; Figures 9A,B).

\section{DISCUSSION}

The present study in male normotensive rats focused on the responses elicited by local Ang II administration within the NTS, the principal site for the termination of baroreceptor afferent fibers mediating the inhibitory effect of baroreceptors on sympathetic outflow. It is well-established from earlier studies by several groups of investigators that microinjection of Ang II into the NTS blunts the sensitivity of the baroreflex (Averill and Diz, 2000; Wong et al., 2002; Zhang et al., 2009) and that AT1R as well as Ang II containing neurons are present in the NTS (Rettig et al., 1986; Healy et al., 1989). The results of our study provide for the first time direct evidence that Ang II, acting on local AT1Rs, increases local GABA concentrations within the NTS, suggesting that the blood pressure increase which was also observed after Ang II administration is GABA dependent. This is corroborated by the observation that the blood pressure response to Ang II is abolished by co-infusion with a selective $\mathrm{GABA}_{\mathrm{A}}$ receptor antagonist. $\mathrm{GABA}_{\mathrm{A}}$ receptor antagonism alone did not affect blood pressure nor HR when administered unilaterally within NTS, which is in line with previous observations from Shih and Chuang (2007) reporting no changes in blood pressure and $\mathrm{HR}$ even after bilateral $\mathrm{GABA}_{\mathrm{A}}$ receptor antagonism within 

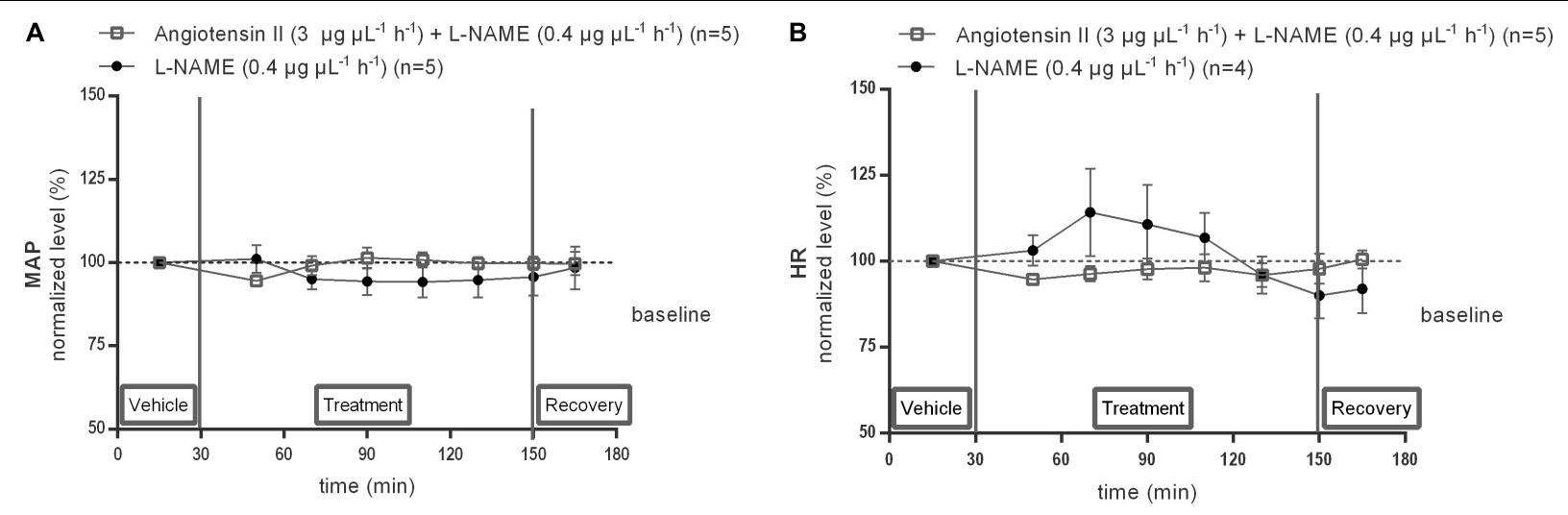

FIGURE 9 | Effect of co-infusion of L-NAME with Ang II (120-240 min) within the NTS on MAP (A) and HR (B). Baseline MAP and HR were respectively, $91 \pm 10 \mathrm{mmHg}$ and $477 \pm 112 \mathrm{bpm}\left(\mathrm{L}-\mathrm{NAME} 0.4 \mu \mathrm{g} \mu \mathrm{L}^{-1} \mathrm{~h}^{-1}\right) ; 98 \pm 21 \mathrm{mmHg}$ and $401 \pm 72 \mathrm{bpm}\left(\right.$ Ang $\left.\| ; 3 \mu \mathrm{g} \mu \mathrm{L}^{-1} \mathrm{~h}^{-1}+\mathrm{L}^{-N A M E ~} 0.4 \mu \mathrm{g} \mu \mathrm{L}^{-1} \mathrm{~h}^{-1}\right)$. Data are shown as the mean percentage of baseline levels \pm SEM. Statistical analysis is performed using the Friedman test and the Dunnett's mutiple comparison test.

the NTS (Shih and Chuang, 2007). Further, our results also show that local NO is involved in the GABA response to AT1R stimulation within the NTS.

We observed, in anesthetized rats, no change in blood pressure nor $\mathrm{HR}$ in response to unilateral administration of $1 \mu \mathrm{g} \mu \mathrm{L}^{-1} \mathrm{~h}^{-1}$ of Ang II, but a significant increase in blood pressure without a change in HR after infusion of $3 \mu \mathrm{g} \mu \mathrm{L}^{-1} \mathrm{~h}^{-1}$ of Ang II. These blood pressure changes were abolished by co-infusion of the selective AT1R antagonist candesartan. These results appear to be in line with earlier studies by other groups on the cardiovascular effects of microinjections of Ang II into the NTS (Rettig et al., 1986). Rettig et al. (1986) reported that microinjections of a low dose of Ang II resulted in a depressor response, whereas higher doses were characterized by a biphasic response, with an initial short lasting depressor response followed by a subsequent increase in blood pressure (Rettig et al., 1986). In our experiments, where no bolus injection of Ang II was given but where Ang II was infused through the microdialysis probe, a putative initial transitory depressor phase was probably undetectable, but we observed also a progressive increase in blood pressure. Other research groups have reported either depressor or pressor responses to microinjections of Ang II (Casto and Phillips, 1984a,b). Overall, it appears from different studies with microinjections of Ang II into the NTS that responses to Ang II display a complex dose-response relationship and that it can produce decreases or increases in blood pressure depending on the infusion dose used, the volume injected, and the exact region of the injection (Yao et al., 2008; Zhang et al., 2009). Such qualitatively different responses could be conceivable with the hypothesis that Ang II may not act as a neurotransmitter itself but rather as a neuromodulator within the NTS, and that effects may differ according to differences in activation states of the different neurons and pathways involved in the regulation of sympathetic tone.

Our observation that central administration of Ang II increased blood pressure without concomitant elevation of $\mathrm{HR}$ was also previously reported by several other investigators, even after bilateral injection (Bruner et al., 1985; Sagara et al., 2007;
Zhang et al., 2009). A possible explanation is that the Ang II mediated increase in blood pressure may trigger baroreflex mediated cardiovascular responses, buffering a putative tachycardic response and also dampening the blood pressure increase, in particular as the contralateral NTS remained intact during our experiments with unilateral administration of Ang II.

The major novel finding of the present study is that local administration of Ang II using microdialysis in conscious normotensive rats induced a significant increase in local GABA concentrations within the NTS. The GABA concentrations returned to baseline levels shortly after stopping the Ang II infusion. The GABA response to Ang II was completely abolished by local co-infusion with the AT1R antagonist candesartan, indicating that this GABA response was mediated through stimulation of local AT1R. Whereas candesartan abolished the responses evoked by exogenous Ang II, we did not observe an effect of candesartan itself on blood pressure or GABA levels. This suggests that, at least in our experimental setting, endogenous activation of AT1R within the NTS does not appear to contribute significantly to the control of GABA release and blood pressure in these baseline conditions in normotensive rats. Ang II and the AT1R antagonist did not significantly affect local glutamate concentrations in the NTS.

It is therefore tempting to postulate that the well-established dampening effect on the baroreceptor reflex of local administration of Ang II is dependent on this AT1R mediated increased release of GABA. Reduction in baroreceptor feedback could indeed be due to inhibition of the transmission between baroreceptor afferents and second-order neurons in the NTS, mediated by pre-and post-synaptic inhibition by GABA (Guyenet, 2006). GABAergic systems are indeed known to play a key role in cardiovascular regulation via $\mathrm{GABA}_{\mathrm{A}}$ and $\mathrm{GABA}_{\mathrm{B}}$ receptors in the NTS (Yao et al., 2008). GABA was shown to be a potent modulator of neurons in the NTS, which contains a high density of $\mathrm{GABA}_{\mathrm{A}}$ and $\mathrm{GABA}_{\mathrm{B}}$ receptor containing neurons and a high density of GABA containing nerve terminals (Zhang et al., 2009). GABA receptor agonists elicit a pressor response when injected into the NTS and $\mathrm{GABA}_{\mathrm{B}}$ receptor 
antagonism results is a depressor response (Zhang et al., 2009). Paton et al. (2001a) reported that the attenuation of the cardiac vagal and sympathetic components of the baroreceptor reflex by Ang II was antagonized by $\mathrm{GABA}_{\mathrm{A}}$ receptor antagonism with bicuculline (Paton et al., 2001a). The same group of investigators also reported in an earlier paper that GABAergic synaptic transmission was potentiated by bath application of Ang II in a subpopulation of NTS neurons recorded intracellularly in vitro (Paton and Kasparov, 1999). Based on these in vitro findings, they suggested that Ang II might cause an increase in release of GABA from terminals of GABAergic neurons (Paton and Kasparov, 1999). Our in vivo results are in line with this hypothesis.

Taken together, these findings reported in the literature combined with our novel direct observation of AT1R mediated increase in GABA concentrations within the NTS suggest that GABA has a crucial role in the dampening effect of Ang II on the baroreceptor reflex.

In normal physiological circumstances, in the absence of exogenous Ang II administration, an increase in blood pressure activates baroreceptors located in the vessel wall of the arteria carotis and the aortic arch, ultimately leading to suppression of the sympathetic tone. The baroreceptor afferents activate NTS efferent glutamatergic neurons which connect to and activate the GABAergic neurons within the CVLM. These GABAergic nerve terminals originating in the CVLM inhibit the activity of the glutamatergic neurons within the RVLM that drive the sympathetic tone. Hence, the NTS neurons inhibit the RVLM indirectly through the activation of these inhibitory GABAergic nerve terminals originating in the CVLM (Guyenet, 2006). Local GABA release within the NTS, as induced by AT1R stimulation by Ang II, can be expected to increase inhibitory GABAergic neurotransmission and reduce the activity of glutamatergic NTS neurons and, subsequently, the activation of the inhibitory GABA neurons in the CVLM, leading to less suppression of the RVLM neurons that drive the sympathetic tone. The final result is inhibition of baroreceptor afferent input signals triggered by increased blood pressure and less suppression of sympathetic tone or, in other words, the well-documented dampening of the baroreflex by Ang II. Through this GABA dependent mechanism, with increased release of GABA within the NTS and, indirectly, reduced release from GABA by CVLM neurons, Ang II can interfere with short term blood pressure fluctuations, but could also lead to a baroreceptor resetting within the NTS resulting in an upregulation of the activity of the RVLM neurons and development of hypertension.

Based on the current evidence, we could hypothesize that Ang II directly activates presynaptic AT1R located on GABAergic (inter)neurons within the NTS resulting in an increase in GABA release. An alternative possibility is that the Ang II mediated release of GABA from local inhibitory GABAergic interneurons within the NTS occurs indirectly and that Ang II stimulates the release of $\mathrm{NO}$ which is then responsible for increased GABA release. Our observation that the AT1R mediated increase in GABA within the NTS is abolished by co-infusion of the NOS inhibitor L-NAME supports this latter possibility and is also in line with previous evidence from different research groups (Paton et al., 2001a; Guyenet, 2006).
Ang II can indeed stimulate NO release (Millatt et al., 1999), and an NO donor microinjected into the NTS was shown to depress the baroreceptor reflex in an in situ 'working heart-brainstem preparation' (Paton et al., 2001a). Moreover, microinjection of $N(\omega)$-methyl-L-arginine acetate (L-NMMA), another NOS inhibitor, was shown by Paton et al. (2001a) to abolish the effect of Ang II on baroreflex function (Paton et al., 2001a). Our observation that NOS inhibition abolished the GABA response and the blood pressure response to Ang II administered into the NTS indicates that this AT1R mediated effect within the NTS is dependent on local NO release, either from neuronal $(\mathrm{n})$ or endothelial (e) origin. NO producing cells and both, n-NOS and e-NOS, are indeed present within the NTS, and AT1Rs were reported to be co-localized with e-NOS in both neurons and endothelial cells (Dun et al., 1994, 1995; Paton et al., 2001a). Previous studies suggest that also circulating Ang II may modulate the baroreflex (Tan et al., 2007; Paton et al., 2008). Circulating Ang II was indeed suggested to reduce the transmission between baroreceptor afferents and NTS efferent neurons by activation of endothelial AT1R, causing the release of NO which in turn potentiates GABA release within the NTS (Paton et al., 2001a,b; Guyenet, 2006). Similarly, NO has also been shown to inhibit neuronal activity through enhanced GABA release in other centers within the medulla oblongata including the PVN (Li et al., 2002, 2003, 2004).

We also observed that local administration of the NOS inhibitor L-NAME alone tended to decrease GABA concentrations within the NTS suggesting the presence of an endogenous tone stimulating GABA release, in agreement with earlier suggestions based on gene transfer studies in conscious rats that eNOS is constitutively active within the NTS in conscious rats as a factor regulating baroreceptor reflex gain (Waki et al., 2003). This is also in line with earlier observations of $\mathrm{Li}$ et al. (2003), using in vitro patch clamp recordings from RVLM projecting PVN neurons, that basal GABAergic neuronal firing activity was reduced by NOS inhibition ( $\mathrm{Li}$ et al., 2003). It is also consistent with previous in vivo studies showing that NOS inhibitors within the PVN increase renal sympathetic discharge (Zhang et al., 1997, 2001).

Our observation that NOS inhibition per se also significantly reduced baseline glutamate levels within the NTS suggests that endogenously formed $\mathrm{NO}$ also stimulates glutamate release, and is in line with earlier findings by Matsuo et al. (2001) that NO production, evoked by $N$-methyl$\mathrm{D}$ aspartate (NMDA) receptor stimulation, can increase glutamate release within the NTS (Matsuo et al., 2001). In the hippocampus also, NO formation in response to NMDA receptor activation was reported to enhance presynaptic glutamate release trough increased cyclic guanosine monophosphate formation (Neitz et al., 2011). Our results therefore corroborate earlier observations that NO can increase the release of GABA as well as of glutamate in different autonomic centers and, hence, is an important neuromodulator (Zanzinger, 2002).

The present study has some limitations. Sevoflurane, which was used for this anesthesia, is known to reduce blood pressure 
(Tsikas et al., 2015). However, our experimental protocol for MAP measurement was designed in a way to include a recovery period after cannulation of the carotid artery as well as a baseline period before test compound administration allowing us to have stable blood pressure before starting the administration of pharmacological compounds. Furthermore, the influence of sevoflurane was present and remained constant, during the whole study period: baseline, during test compound (in the control situation) and after withdrawal of test compounds. These experimental conditions allowed us to detect a hypertensive response (change from baseline) mediated by AT1R stimulation within the NTS compared to baseline measurement. Similarly, in other studies in the same experimental setting, a hypotensive response induced by clonidine administration was reproducibly demonstrated, as expected (data not shown). Therefore, even under anesthesia, short term changes in blood pressure induced by interventions such as Ang II administration, can be reproducibly detected and assessed with direct continuous monitoring of blood pressure. We used L-NAME, a non-selective NOS inhibitor in the present study to demonstrate that the AT1R mediated effect on GABA release is dependent on an intact NO pathway. It would be of interest to further investigate the NO involved is from neuronal or endothelial origin using more selective e- versus n-NOS inhibitors. In addition, as the NTS densely expresses AT2R which are mainly located on GABA neurons (de Kloet et al., 2016), further research exploring the possible effects of AT2R stimulation within the NTS on GABA levels and blood pressure seems warranted. It has indeed been hypothesized that AT2R stimulation on GABA neurons within the NTS may act to inhibit GABA release, thereby reducing the tonic inhibition of baroreflex pathways provided by these GABAergic neurons, eventually reducing blood pressure (Steckelings et al., 2017).

We conclude that Ang II mediated stimulation of AT1Rs within the NTS results in activation of either eNOS or nNOS (or both), with a subsequent local production of NO, which enhances GABA release probably from NTS interneurons. We speculate that this release of GABA within the NTS inhibits glutamatergic neurons projecting to the CVLM, thereby reducing the activation of the CVLM inhibitory GABAergic nerves with subsequent disinhibition of the sympathetic driving glutamatergic neurons in the RVLM. Our results further suggest that NO produced within the NTS tonically potentiates local GABA and glutamate release, and may therefore also be an important modulator of the central blood pressure regulation.

\section{REFERENCES}

Averill, D. B., and Diz, D. I. (2000). Angiotensin peptides and baroreflex control of sympathetic outflow: pathways and mechanisms of the medulla oblongata. Brain Res. Bull. 51, 119-128. doi: 10.1016/s0361-9230(99)00237-3

Bailey, T. W., Appleyard, S. M., Jin, Y. H., and Andersen, M. C. (2008). Organization and properties of GABAergic neurons in solitary tract nucleus (NTS). J. Neurophysiol. 99, 1712-1722. doi: 10.1152/jn.00038.2008

Benveniste, H., and Diemer, N. H. (1987). Cellular reactions to implantation of a microdialysis tube in the rat hippocampus. Acta Neuropathol. 74, 234-238. doi: $10.1007 /$ bf00688186

\section{ETHICS STATEMENT}

This study was carried out in accordance with the recommendations of "National and European guidelines for animal experimental research, Ethical Committee for Animal Experiments of the Vrije Universiteit Brussel, Belgium." The protocol was approved by the "Ethical Committee for Animal Experiments of the Vrije Universiteit Brussel, Belgium."

\section{AUTHOR CONTRIBUTIONS}

LL performed the research and wrote the research manuscript. IS and $\mathrm{AD}$ designed the research study and gave critical insights in the research manuscript.

\section{FUNDING}

This research was supported by the Research Council of the Vrije Universiteit Brussel, the Cardiovascular Research Cluster of the University Hospital of Brussels (UZ Brussel), the Department of Pharmaceutical Chemistry, Drug Analysis and Drug Information and the Department of Clinical Pharmacology and Clinical Pharmacy, respectively headed by Prof. Dr. Apr. I. Smolders and Prof. Dr. A. G. Dupont.

\section{ACKNOWLEDGMENTS}

The authors acknowledge the excellent assistance for the analysis of glutamate and GABA by liquid chromatography of Mrs. R. Berckmans and Mrs. C. De Rijck, the technical assistance for surgeries of Mr. G. De Smet, the biotechnical support for monitoring blood pressure and HR of Mr. M. Vervoort and the statistical advice of Mr. S. Van Laere.

\section{SUPPLEMENTARY MATERIAL}

The Supplementary Material for this article can be found online at: https://www.frontiersin.org/articles/10.3389/fphar. 2019.00460/full\#supplementary-material

FIGURE S1 | Histological verification of the probe localization by a neutral red staining compared against an anatomic atlas (Paxinos and Watson, 1998).

Brouwers, S., Smolders, I., Wainford, R. D., and Dupont, A. G. (2015). Hypotensive and sympathoinhibitory responses to selective central AT2 receptor stimulation in spontaneously hypertensive rats. Clin. Sci. 129, 81-92. doi: 10.1042/ CS20140776

Bruner, C. A., Weaver, J. M., and Fink, G. D. (1985). Sodium-dependent hypertension produced by chronic central angiotensin II infusion. Am. J. Physiol. 249, H321-H327. doi: 10.1152/ajpheart.1985.249.2. $\mathrm{H} 321$

Casto, R., and Phillips, M. I. (1984a). Cardiovascular actions of microinjections of angiotensin II in the brain stem of rats. Am. J. Physiol. 246, R811-R816. doi: 10.1152/ajpregu.1984.246.5.R811 
Casto, R., and Phillips, M. I. (1984b). Mechanism of pressor effects by angiotensin in the nucleus tractus solitarius of rats. Am. J. Physiol. 247, R575-R581. doi: 10.1152/ajpregu.1984.247.3.R575

de Kloet, A. D., Wang, L., Ludin, J. A., Smith, J. A., Pioquinto, D. J., Hiller, H., et al. (2016). Reporter mouse strain provides a novel look at angiotensin type2 receptor distribution in the central nervous system. Brain Struct. Funct. 221, 891-912. doi: 10.1007/s00429-014-0943-1

Dufour, A., Tell, F., and Baude, A. (2010). Perinatal development of inhibitory synapses in the nucleus tractus solitarii of the rat. Eur. J. Neurosci. 32, 538-549. doi: 10.1111/j.1460-9568.2010.07309.x

Dun, N. J., Dun, S. L., and Forstermann, U. (1994). Nitric oxide synthase immunoreactivity in rat pontine medullary neurons. Neuroscience 59, 429-445. doi: 10.1016/0306-4522(94)90607-6

Dun, N. J., Dun, S. L., Hwang, L. L., and Fôrstermann, U. (1995). Infrequent coexistence of nitric oxide synthase and parvalbumin, calbindin and calretinin immunoreactivity in rat pontine neurons. Neurosci. Lett. 191, 165-168. doi: 10.1016/0304-3940(95)11582-h

Dupont, A. G., and Brouwers, S. (2010). Brain angiotensin peptides regulate sympathetic tone and blood pressure. J. Hypertens. 28, 1599-1610. doi: 10.1097/ HJH.0b013e32833af3b2

Ferguson, A. V., Washburn, D. L., and Latchford, K. J. (2001). Hormonal and neurotransmitter roles for angiotensin in the regulation of central autonomic function. Exp. Biol. Med. 226, 85-96. doi: 10.1177/153537020122600205

Grabb, M. C., Sciotti, V. M., Gidday, J. M., Cohen, S. A., and van Wylen, D. G. (1998). Neurochemical and morphological responses to acutely and chronically implanted brain microdialysis probes. J. Neurosci. Methods 82, 25-34. doi: 10.1016/s0165-0270(98)00025-9

Guyenet, P. G. (2006). The sympathetic control of blood pressure. Nat. Rev. Neurosci. 7, 335-346. doi: 10.1038/nrn1902

Healy, D. P., Rettig, R., Nguyen, T., and Printz, M. P. (1989). Quantitative autoradiography of angiotensin II receptors in the rat solitary-vagal area: effects of nodose ganglionectomy or sinoaortic denervation. Brain Res. 484, 1-12. doi: 10.1016/0006-8993(89)90343-0

Hu, L., Zhu, D. N., Yu, Z., Wang, J. Q., Sun, Z. J., Yao, T., et al. (2002). Expression of angiotensin II type 1 (AT(1)) receptor in the rostral ventrolateral medulla in rats. J. Appl. Physiol. 92, 2153-2161. doi: 10.1152/japplphysiol.00261.2001

Kilkenny, C., Browne, W. J., Cuthill, I. C., Emerson, M., and Altman, D. G. (2010). Improving bioscience research reporting: the ARRIVE guidelines for reporting animal research. PLoS Biol. 8:e1000412. doi: 10.1371/journal.pbio.1000412.

Légat, L., Brouwers, S., Smolders, I., and Dupont, A. G. (2017). Hypotensive response to angiotensin II type 2 receptor stimulation in the rostral ventrolateral medulla requires functional GABA-A receptors. Front. Neurosci. 11:346. doi: 10.3389/fnins.2017.00346

Li, D. P., Chen, S. R., Finnegan, T. F., and Pan, H. L. (2004). Signalling pathway of nitric oxide in synaptic GABA release in the rat paraventricular nucleus. J. Physiol. 554, 100-110. doi: 10.1113/jphysiol.2003.053371

Li, D. P., Chen, S. R., and Pan, H. L. (2002). Nitric oxide inhibits spinally projecting paraventricular neurons through potentiation of presynaptic GABA release. J. Neurophysiol. 88, 2664-2674. doi: 10.1152/jn.00540.2002

Li, Y., Zhang, W., and Stern, J. E. (2003). Nitric oxide inhibits the firing activity of hypothalamic paraventricular neurons that innervate the medulla oblongata: role of GABA. Neuroscience 118, 585-601. doi: 10.1016/s0306-4522(03) 00042-3

Li, Y. F., Wang, W., Mayhan, W. G., and Patel, K. P. (2006). Angiotensinmediated increase in renal sympathetic nerve discharge within the PVN: role of nitric oxide. Am. J. Physiol. Regul. Integr. Comp. Physiol. 290, R1035-R1043. doi: 10.1152/ajpregu.00338.2004

Matsumura, K., Averill, D. B., and Ferrario, C. M. (1998). Angiotensin II acts at AT1 receptors in the nucleus of the solitary tract to attenuate the baroreceptor reflex. Am. J. Physiol. 275, R1611-R1619. doi: 10.1152/ajpregu.1998.275.5.R1611

Matsuo, I., Hirooka, Y., Hironaga, K., Eshima, K., Shigematsu, H., Shihara, M., et al. (2001). Glutamate release via NO production evoked by NMDA in the NTS enhances hypotension and bradycardia in vivo. Am. J. Physiol. Regul. Integr. Comp. Physiol. 280, R1285-R1291. doi: 10.1152/ajpregu.2001.280.5.R1285

Mei, L., Zhang, J., and Mifflin, S. (2003). Hypertension alters GABA receptormediated inhibition of neurons in the nucleus of the solitary tract. Am. J. Physiol. Regul. Integr. Comp. Physiol. 285, R1276-R1286. doi: 10.1152/ajpregu. 00255.2003
Mertens, B., Vanderheyden, P., Michotte, Y., and Sarre, S. (2010). Direct angiotensin II type 2 receptor stimulation decreases dopamine synthesis in the rat striatum. Neuropharmacology 58, 1038-1044. doi: 10.1016/j.neuropharm. 2010.01.009

Millatt, L. J., Abdel-Rahman, E. M., and Siragy, H. M. (1999). Angiotensin II and nitric oxide: a question of balance. Regul. Pept. 81, 1-10. doi: 10.1016/s01670115(99)00027-0

Neitz, A., Mergia, E., Eysel, U. T., Koesling, D., and Mittmann, T. (2011). Presynaptic nitric oxide/cGMP facilitates glutamate release via hyperpolarization-activated cyclic nucleotide-gated channels in the hippocampus. Eur. J. Neurosci. 33, 1611-1621. doi: 10.1111/j.1460-9568.2011. 07654.x

Ogawa, H., Mizusawa, A., Kikuchi, Y., Hida, W., Miki, H., Shirato, K., et al. (1995). Nitric oxide as a retrograde messenger in the nucleus tractus solitarii of rats during hypoxia. J. Physiol. 486(Pt 2), 495-504. doi: 10.1113/jphysiol.1995. sp020828

Paton, J. F., Boscan, P., Murphy, D., and Kasparov, S. (2001a). Unravelling mechanisms of action of angiotensin II on cardiorespiratory function using in vivo gene transfer. Acta Physiol. Scand. 173, 127-137. doi: 10.1046/j.1365201X.2001.00898.x

Paton, J. F., Deuchars, J., Ahmad, Z., Wong, L. F., Murphy, D., and Kasparov, S. (2001b). Adenoviral vector demonstrates that angiotensin II-induced depression of the cardiac baroreflex is mediated by endothelial nitric oxide synthase in the nucleus tractus solitarii of the rat. J. Physiol. 531, 445-458. doi: 10.1111/j.1469-7793.2001.0445i.x

Paton, J. F., and Kasparov, S. (1999). Differential effects of angiotensin II on cardiorespiratory reflexes mediated by nucleus tractus solitarii - a microinjection study in the rat. J. Physiol. 521(Pt 1), 213-225. doi: 10.1111/j. 1469-7793.1999.00213.x

Paton, J. F., Wang, S., Polson, J. W., and Kasparov, S. (2008). Signalling across the blood brain barrier by angiotensin II: novel implications for neurogenic hypertension. J. Mol. Med. 86, 705-710. doi: 10.1007/s00109-008-0324-324

Paxinos, G., and Watson, S. (1998). The Rat Brain in Stereotaxic Coordinates. San Diego, CA: Academic Press.

Potts, J. T., Paton, J. F., Mitchell, J. H., Garry, M. G., Kline, G., Anguelov, P. T., et al. (2003). Contraction-sensitive skeletal muscle afferents inhibit arterial baroreceptor signalling in the nucleus of the solitary tract: role of intrinsic GABA interneurons. Neuroscience 119, 201-214. doi: 10.1016/s0306-4522(02) 00953-3

Rettig, R., Healy, D. P., and Printz, M. P. (1986). Cardiovascular effects of microinjections of angiotensin II into the nucleus tractus solitarii. Brain Res. 364, 233-240. doi: 10.1016/0006-8993(86)90835-8

Sagara, Y., Hirooka, Y., Nozoe, M., Ito, K., Kimura, Y., Sunagawa, K., et al. (2007). Pressor response induced by central angiotensin II is mediated by activation of Rho/Rho-kinase pathway via AT1 receptors. J. Hypertens. 25, 399-406. doi: 10.1097/HJH.0b013e328010b87f

Schiffer, W. K., Mirrione, M. M., Biegon, A., Alexoff, D. L., Patel, V., and Dewey, S. L. (2006). Serial microPET measures of the metabolic reaction to a microdialysis probe implant. J. Neurosci. Methods 155, 272-284. doi: 10.1016/j. jneumeth.2006.01.027

Shih, C. D., and Chuang, Y. C. (2007). Nitric oxide and GABA mediate bidirectional cardiovascular effects of orexin in the nucleus tractus solitarii of rats. Neuroscience 149, 625-635. doi: 10.1016/j.neuroscience.2007.07.016

Smolders, I., De Klippel, N., Sarre, S., Ebinger, G., and Michotte, Y. (1995a). Tonic GABA-ergic modulation of striatal dopamine release studied by in vivo microdialysis in the freely moving rat. Eur. J. Pharmacol. 284, 83-91. doi: 10.1016/0014-2999(95)00369-v

Smolders, I., Sarre, S., Michotte, Y., and Ebinger, G. (1995b). The analysis of excitatory, inhibitory and other amino acids in rat brain microdialysates using microbore liquid chromatography. J. Neurosci. Methods 57, 47-53. doi: 10. 1016/0165-0270(94)00124-y

Steckelings, U. M., Kloet, A., and Sumners, C. (2017). Centrally mediated cardiovascular actions of the angiotensin II type 2 receptor. Trends Endocrinol. Metab. 28, 684-693. doi: 10.1016/j.tem.2017.06.002

Sumbria, R. K., Klein, J., and Bickel, U. (2011). Acute depression of energy metabolism after microdialysis probe implantation is distinct from ischemiainduced changes in mouse brain. Neurochem. Res. 36, 109-116. doi: 10.1007/ s11064-010-0276-272 
Tagawa, T., and Dampney, R. A. (1999). AT(1) receptors mediate excitatory inputs to rostral ventrolateral medulla pressor neurons from hypothalamus. Hypertension 34, 1301-1307. doi: 10.1161/01.hyp.34.6.1301

Tan, P. S., Killinger, S., Horiuchi, J., and Dampney, R. A. (2007). Baroreceptor reflex modulation by circulating angiotensin II is mediated by AT1 receptors in the nucleus tractus solitarius. Am. J. Physiol. Regul. Integr. Comp. Physiol. 293, R2267-R2278. doi: 10.1152/ajpregu.00267.2007

Tan, P. S., Potas, J. R., Killinger, S., Horiuchi, J., Goodchild, A. K., Pilowsky, P. M., et al. (2005). Angiotensin II evokes hypotension and renal sympathoinhibition from a highly restricted region in the nucleus tractus solitarii. Brain Res. 1036, 70-76. doi: 10.1016/j.brainres.2004.12.018

Tsikas, D., Jordan, J., and Engeli, S. (2015). Blood pressure-lowering effects of propofol or sevoflurane anaesthesia are not due to enhanced nitric oxide formation or bioavailability. Br. J. Clin. Pharmacol. 79, 1030-1033. doi: 10.1111/ bcp. 12568

Van Hemelrijck, A., Sarre, S., Smolders, S., and Michotte, Y. (2005). Determination of amino acids associated with cerebral ischaemia in rat brain microdialysates using narrowbore liquid chromatography and fluorescence detection. J. Neurosci. Methods 144, 63-71. doi: 10.1016/j.jneumeth.2004.10.013

Vitela, M., and Mifflin, S. W. (2001). Gamma-aminobutyric acid(B) receptormediated responses in the nucleus tractus solitarius are altered in acute and chronic hypertension. Hypertension 37, 619-622. doi: 10.1161/01.hyp.37.2.619

Waki, H., Kasparov, S., Wong, L. F., Murphy, D., Shimizu, T., Paton, J. F., et al. (2003). Chronic inhibition of endothelial nitric oxide synthase activity in nucleus tractus solitarii enhances baroreceptor reflex in conscious rats. J. Physiol. 546, 233-242. doi: 10.1113/jphysiol.2002.030270

Wong, L. F., Polson, J. W., Murphy, D., Paton, J. F., and Kasparov, S. (2002). Genetic and pharmacological dissection of pathways involved in the angiotensin II-mediated depression of baroreflex function. FASEB J. 16, 1595-1601. doi: 10.1096/fj.02-0099com

Yang, S. N., Lippoldt, A., Jansson, A., Phillips, M. I., Ganten, D., Fuxe, K., et al. (1997). Localization of angiotensin II AT1 receptor-like immunoreactivity in catecholaminergic neurons of the rat medulla oblongata. Neuroscience 81, 503-515. doi: 10.1016/s0306-4522(97)00057-2

Yao, F., Sumners, C., O'Rourke, S. T., and Sun, C. (2008). Angiotensin II increases $\mathrm{GABAB}$ receptor expression in nucleus tractus solitarii of rats. Am. J. Physiol. Heart Circ. Physiol. 294, H2712-H2720. doi: 10.1152/ajpheart.00729. 2007

Zanzinger, J. (2002). Mechanisms of action of nitric oxide in the brain stem: role of oxidative stress. Auton. Neurosci. 98, 24-27. doi: 10.1016/s1566-0702(02) 00025-5

Zhang, K., Li, Y. F., and Patel, K. P. (2001). Blunted nitric oxide-mediated inhibition of renal nerve discharge within PVN of rats with heart failure. Am. J. Physiol. Heart Circ. Physiol. 281, H995-H1004. doi: 10.1152/ajpheart.2001.281. 3.H995

Zhang, K., Mayhan, W. G., and Patel, K. P. (1997). Nitric oxide within the paraventricular nucleus mediates changes in renal sympathetic nerve activity. Am. J. Physiol. 273, R864-R872. doi: 10.1152/ajpregu.1997.273.3. R864

Zhang, Q., Yao, F., O’Rourke, S. T., Qian, S. Y., and Sun, C. (2009). Angiotensin II enhances GABA(B) receptor-mediated responses and expression in nucleus tractus solitarii of rats. Am. J. Physiol. Heart Circ. Physiol. 297, H1837-H1844. doi: 10.1152/ajpheart.00354.2009

Conflict of Interest Statement: The authors declare that the research was conducted in the absence of any commercial or financial relationships that could be construed as a potential conflict of interest.

Copyright (c) 2019 Légat, Smolders and Dupont. This is an open-access article distributed under the terms of the Creative Commons Attribution License (CC BY). The use, distribution or reproduction in other forums is permitted, provided the original author(s) and the copyright owner(s) are credited and that the original publication in this journal is cited, in accordance with accepted academic practice. No use, distribution or reproduction is permitted which does not comply with these terms. 